\title{
Catalytic Encounters at the Molecular Level: Gabor A. Somorjai Award Symposium for Creative Research in Catalysis in Honor of Professor Manos Mavrikakis
}

\author{
Ye Xu' ${ }^{1}$. Lars C. Grabow ${ }^{2}$
}

Published online: 8 August 2020

(c) Springer Science+Business Media, LLC, part of Springer Nature 2020

This Special Issue is dedicated to Prof. Manos Mavrikakis, in honor of his receiving the 2019 Gabor A. Somorjai Award for Creative Research in Catalysis at the 257th American Chemical Society Meeting in Orlando, Florida.

Prof. Mavrikakis is a pioneer of using quantum mechanical calculations and mathematical modeling to reinvigorate the catalytic science. He has made significant contributions to the field by advancing the fundamental, molecular-level understanding of the water gas shift reaction, methanol synthesis, preferential oxidation of $\mathrm{CO}$ in $\mathrm{H}_{2}$, electro-oxidation of methanol, dimethyl ether and ammonia, and the oxygen reduction reaction, and by developing the concept of surface and near surface alloys as a way to achieve catalysts by design. His creative ideas and contributions are seen underlying many of the most active areas of catalysis research today, including $\mathrm{C} 1$ conversion and electrocatalysis, and have motivated new synthesis routes for precisely defined active sites.

The contributed articles to this Special Issue in many ways reflect Prof. Mavrikakis' influence on the field of catalysis. For instance, as one of the first proponents of monolayer surface alloys he laid the foundation that motivated the synthesis and detailed kinetic investigations of metal alloys with well-defined active sites and unique properties. One or more aspects of this ground-breaking work are mirrored in the contributions by Profs. Flytzani-Stephanopoulos, Xia, Xu, Grabow, and Adzic. The articles by Profs.

\footnotetext{
$\mathrm{YeXu}$

yexu@lsu.edu

$\bowtie$ Lars C. Grabow

grabow@uh.edu

1 Cain Department of Chemical Engineering, Louisiana State University, Baton Rouge, LA 70803, USA

2 Department of Chemical \& Biomolecular Engineering, University of Houston, 4726 Calhoun Rd, Houston, TX 77204, USA
}

Dumesic and Huber, Greeley, and Adzic are a homage to the exemplary demonstrations of marrying theory and experimentation in the bulk of Mavrikakis' work. Here, microkinetic modeling plays a key role in relating atomic-scale insight to experimental observations, which is the path followed in the contributions by Profs. Nørskov, Greeley, and Rangarajan. Finally, Prof. Mavrikakis' meticulous attention to detail is echoed in all the articles of this Special Issue, and in the context of carefully conducted first-principles simulations we highlight the manuscripts by Profs. Venvik and Celik, and of course the Awardee himself.

As former members of the group, we are forever indebted to Prof. Mavrikakis. He always leads by example and sets the bar for hard work and service, he instills a strong spirit of scientific rigor in his mentees, and he has provided unwavering support for our careers. To the catalysis community he is a tireless champion for theory and computation. His effort has been instrumental in establishing the credibility and predictive power of first principles calculations in catalysis research.

In closing, we would like to thank all participants in the award symposium and the celebration afterwards for a truly memorable event, and thank all authors who contributed to this Special Issue. Finally, we would like to thank Prof. Gabor Somorjai for his leadership and support of the Somorjai Award for Creative Research in Catalysis, for contributing a perspective on unifying concepts across homogeneous, heterogeneous and enzyme catalysis, and for inviting us to be the guest editors of this Special Issue of Topics in Catalysis.

Publisher's Note Springer Nature remains neutral with regard to jurisdictional claims in published maps and institutional affiliations. 